\title{
Mixtape: Música, masculinidad y emociones en $E l$ amor nos destrozará de Diego Erlan y Ocio de Fabián Casas*
}

\section{Catalina Forttes Zalaquett**}

\section{Resumen}

Este trabajo examina el papel de la música pop-rock anglosajona en la vida emocional de personajes masculinos en las novelas argentinas Ocio (2000) de Fabián Casas y El amor nos destrozará (2012) de Diego Erlan. En estas novelas la música y sus modalidades de consumo otorgan a los protagonistas herramientas emocionales para enfrentar no sólo la crisis identitaria adolescente, sino también la experiencia del duelo. Leo las novelas de Erlan y Casas como "autoficciones formativas" en las que convergen dos pactos de lectura: el autobiográfico y el novelesco y el uso de un recurso autoreferencial como una forma protopolítica de poner en circulación una sensibilidad masculina que no encuentra sino en la música un lenguaje capaz de codificar emociones que escapan a la normativa de género patriarcal.

Palabras clave: Novela Argentina, música, emociones, masculinidad.

\section{Mixtape: Music, Masculinity and Emotion in El amor nos destrozará by Diego Erlan y Ocio by Fabián Casas}

\begin{abstract}
This work examines the role of anglo pop-rock music in the emotional life of the male protagonists of Argentinian novels Ocio (2000) by Fabián Casas and El amor nos destrozará 82012) by Diego Erlan. In these novels music and its forms of consumption provide the protagonists the emotional tools to face not only a teenage identity crisis, but also the experience of mourning. I read Erlan's and Casas' novels as "formative self-fictions" that convey two kinds of reading pacts: the one of the novel and the one of the autobiography and where the use of self referential resources act as a proto-political way of circulating the emotional needs of a male sensitivity that does not find, but in music, a language able to codify emotions that escape patriarchal gender norms.
\end{abstract}

Keywords: Argentinian novel, Music, Emotions, Masculinity.

Recibido: 15/o1/2017

Aceptado: 21/06/2017

\footnotetext{
Este artículo forma parte del proyecto “Músico errante: Masculinidades, estéticas y mercados en la música popular y narrativa latinoamericana reciente" No 1141209 de la investigadora Dra. Rubí Carreño y del cual fui co-investigadora.

** Chilena. PhD. en Literatura y Lenguas Hispánicas. Académica de la Pontificia Universidad Católica de Valparaíso, Valparaíso Chile. catalina.forttes@pucv.cl
} 
Representar la experiencia con banda sonora es quizás un sello de la sensibilidad de los años noventa, una generación que por primera vez usó audífonos y reproductores de música y video (VHS) y que, por lo tanto, individualizó una actividad hasta entonces colectiva. Los discos se acumulan en los espacios secretos y privados como los dormitorios y roperos de los jóvenes protagonistas de las novelas argentinas Ocio (2000) de Fabián Casas y El amor nos destrozará (2012) de Diego Erlan, textos donde el consumo de música pop-rock anglosajona funciona como un refugio de un mundo adulto hiriente. Propongo, de este modo, una lectura de estas novelas a partir de la función que cumple la música y sus modalidades de consumo como herramientas emocionales para enfrentar no sólo la crisis identitaria adolescente, sino también la experiencia del duelo. La música de bandas de pop-rock británico matizan así los procesos formativos de los protagonistas de estos textos, jóvenes que se encuentran en un "impasse emocional”, ya que las configuraciones emocionales heredadas no logran orientar una subjetividad masculina joven hacia emociones que puedan ayudarlos a nombrar y a elaborar tanto sus deseos como sus pérdidas.

Leo las novelas de Erlan y Casas como "autoficciones formativas" ya que convergen en ellas dos pactos de lectura: el autobiográfico y el novelesco. Estas son novelas en las cuales se identifican elementos característicos de formación, a la vez que presentan una ilusión autobiográfica que vincula al autor con el narrador y el protagonista. Tanto la autoficción formativa, en la línea de la novela de formación de artista (Kunstlerroman), como la novela autobiográfica, ponen el foco en la forma en que el autor/narrador/personaje construye su subjetividad y la manera en que se inserta (o no) en lo social. Las novelas de Erlan y Casas develan así al lector los procesos de formación emocional de sus protagonistas a la vez que resaltan la importancia de la música como codificadora de una sensibilidad solo descifrable por una ecclesia invisibilis de sensibilidades equivalentes que se construyen a partir del mismo archivo mediático.

En la línea propuesta por R.W. Connell (2005) y Judith Butler (1999), aquí se entiende el género como resultado de un proceso de construcción sujeto a un sistema de poder, lo cual otorga a la influencia de los medios (en este caso la música anglo) un papel ambivalente. Por un lado, las masculinidades mediatizadas por el pop y el rock anglosajones desafían las tradiciones locales al canalizar el deseo adolescente hacia modelos foráneos de rebeldía y erotismo que proveen nuevos lineamientos para la 
expresión del dolor y el sufrimiento. En tanto que, por otro, los medios, al canalizar y codificar afectos inmanentes, neutralizan su potencial disruptivo. ${ }^{1}$ Víctor Seidler en Masculinidades. Culturas globales y vidas íntimas (2007) nos recuerda que la exposición a la cultura globalizada en el contexto latinoamericano del cambio de siglo es constante e inevitable, lo que resulta en un joven expuesto a una diversidad de experiencias masculinas nunca antes vistas. En Ocio y en El amor nos destrozará, los discos de The Beatles, Led Zeppelin y Joy Division funcionan como un refugio personal en el cual se cultiva y prolonga una vida emocional adolescente: el único momento en la vida en el cual la exacerbación de los sentimientos, los excesos y la alienación son permisibles.

Lauren Berlant (2011) define el impasse como un momento en el cual se hace difícil identificar la forma en que una situación se va a desarrollar y evolucionar. El impasse es un estado de parálisis que, a pesar de entenderse generalmente de forma negativa, también sirve de caldo de cultivo para una reconfiguración de las formas tradicionales de reproducir la vida y el trabajo ante una crisis (5). En las obras el impasse se relaciona al impacto del duelo y la carencia de registros que permitan su elaboración. En el caso de Ocio, el impasse se manifiesta por medio de la expresión de un rechazo a las exigencias y prácticas de una masculinidad adulta:

Si tuviera que rotular algunos períodos de mi vida, a mi niñez la ubicaría bajo el título de "la escolástica de mi viejo" y a mi adolescencia como "El Imperio de los Sentidos". Después viene esta parte en la que estoy, una mezcla de adolescencia y juventud, siempre imprecisa, a la que no le encuentro la vuelta. (13)

El potencial reparador de la música en relación a la elaboración del duelo puede ser leído en la línea de lo que Allison Landsberg (2004) llama "memoria prostética". Según Landsberg, los medios masivos funcionan como una interfase entre una persona y una narrativa histórica sobre el pasado, es decir, proveen de imagen y relato a una historia que en muchos casos no se ha experimentado de primera mano, por lo que

Sirve a este trabajo la definición de emociones que hace Jon Beasley-Murray en Afecto y Hegemonía (2008). Aquí Brasley-Murray piensa la emoción como un afecto nombrado, es decir, controlado desde la hegemonía. El afecto es disruptivo, difícil de controlar en tanto que las emociones pueden ser asociadas a individuos específicos. Sarah Ahmed en The Politics of Emotion (2004), hace hincapié en que las emociones son estados que generalemente tienen raza y sexo, por lo que la emocionalidad se ha caracterizado tradicionalmente como femenina y de color en oposición a la racionalidad masculina y blanca. Las emociones son socialmente pactadas en tanto que el afecto es inmanencia tanto individual como colectiva. 
se constituye en ellos uno de los mayores archivos de memoria simbólica de la nación o comunidad (2). El concepto de Landsberg permite pensar la música que emana de la casetera o el Walkman como una prótesis que conecta las subjetividades de los protagonistas de las novelas que analizo con una historia emocional escamoteada que ellos luego codifican en los lenguajes musicales y emocionales del pop y el rock. Si bien la memoria en cuestión no es heredada (como en el marco que ofrece Landsberg), las experiencias traumáticas que ocurren en la vida de los personajes no han sido integradas por falta de un lenguaje que permita su elaboración. Sin embargo, la música que emana de caseteras, Walkmans y tocadiscos funciona en las novelas como contenedora y traductora de afectos relacionados al duelo. Las letras y los acordes reconocibles de las bandas mencionadas arriba otorgan sentido a una memoria fragmentada.

En el caso de El amor nos destrozará el mixtape, o la lista de canciones seleccionadas y grabadas en un casete, construye un paisaje emocional que le permite a su protagonista salvar el impasse emocional en el que se encuentra. La novela expone desde el primer párrafo el imperativo de reconstruir un pasado a partir de los retazos de una memoria infantil: "La historia no empieza así. Ni con gritos ni con llantos ni si quiera cuando la madre le pregunta al chico cómo es el rostro de una mosquita muerta. Quiere acordarse. El chico cierra los ojos, cierra la boca, hace fuerza para recordar algo pero no lo consigue." (9).

Ambas novelas se construyen en torno la muerte de un miembro de la familia del protagonista: la hermana mayor en El amor nos destrozará y la madre en Ocio. Lo que queda después de la muerte de estas mujeres son recuerdos fragmentados que, como se estableció anteriormente, los personajes no logran significar sin la ayuda de la música. En El amor nos destrozará la hermana del protagonista deja unos misteriosos casetes en el fondo de su armario antes de morir, y el ejercicio de memoria se traduce en escuchar y descifrar el mensaje oculto en las canciones grabadas en ellos. De las canciones del mixtape, la que más llega al protagonista es "El amor nos destrozará" de Joy Division ("Love Will Tear Us Apart") la que además de prestar su título a la novela, acompaña al protagonista en su propio proceso formativo, ya que es por medio de la búsqueda del título de la canción y de la banda que, eventualmente, se conecta con sujetos cuya sensibilidad también ha sido educada por el grupo británico. Así, las melodías que en un momento de la vida le daban miedo, con el tiempo se 
transforman en canciones de amor que le dedica su hermana y también en el himno de una tribu de jóvenes, miembros de una ecclesia invisibilis.

\section{Autoficción formativa, novela bonsái y lo íntimo como político}

La autoficción no se entiende aquí como un género narrativo en sí, puesto que se limita a ser una estrategia que se utiliza en estas novelas de formación para representar una "ilusión autobiográfica" que rescata la idea de autor en lugar del autor real, por medio de datos o marcas ancladas en la biografía del autor que, al mezclarse con elementos ficticios y recursos formales de la narrativa, construyen un texto que tiene un aire biográfico pero que funciona como ficción. Así lo expresa Andrés, el protagonista de Ocio: "Inventar, no invento. Recuerdo cosas, historias. Por lo general recuerdo algo y lo modifico. Así es más fácil. Igual me parece que si está todo inventado no vale la pena" (55).

La figura del autor se releva como personaje dejando así de lado la función autoral que tanto Roland Barthes como Michell Foucault clausuraron al final de los sesenta. Fabián Casas en Veteranos del pánico, la nouvelle autobiográfica que se publica conjuntamente con Ocio en la edición de Alpha Decay del 2012, ${ }^{2}$ es transparente con relación a su biografía personal como universo referencial para su obra: "mi terapeuta me había aconsejado que escribiera sobre mis orígenes, para ver si de ese modo podía volver a funcionar. Atenti: Yo no tengo imaginación. Escribí unos poemas y una novelita bonsái sobre situaciones y gente que conozco" (75). El nombre, "novela bonsái”, que le pone Casas al tipo de ficción autobiográfica acotada, resuena luego en la publicación epónima Bonsái (2006) del escritor chileno Alejandro Zambra y con la cual se visibiliza un género que se ha convertido en tendencia dentro de ámbito de las letras más jóvenes conosureñas. La novela "bonsái” se vende como ficción; aun cuando narre hechos y experiencias que podrían vincularse a la biografía de su autor y enfatice ciertas estrategias narrativas como el uso de la primera persona, el tono testimonial y la cercanía o familiaridad con el cronotopo del autor. Formalmente, esta novela tiende al minimalismo y a la brevedad en tanto que sus universos referenciales están íntimamente relacionados con los consumos mediáticos de los autores y por extención

Ambos textos se publican inicialmente el 2000. 
a los personajes de las obras. El lenguaje de las novelas de Erlan y Casas necesita de las referencias mediáticas para evocar emociones, ya que este se caracteriza por su parquedad y economía. De este modo, la música es la encargada de evocar la emocionalidad tanto a nivel de trama como a nivel formal. Las oraciónes cortas de Erlan se transforman mediante las referencias a las canciones de Joy Division en una dimensión misteriosa que conecta al lector con una sensibilidad que también encuentra fuera de la novela:

El cantante estaba muerto. La banda ya no existía y solo habían grabado dos discos y un par de canciones sueltas. Simón me contó que el cantante se llamaba Ian Curtis y se había matado en 1980. El mismo año en que yo nací. Y cuando lo supe, me pareció otra vez que mi hermana sabía algo que jamás nos había dicho. Y hablo en plural porque ni siquiera mis padres imaginaban que esos casetes pudieran existir. Desconocían la música que escuchaba su hija. No sabían. Nada. (151)

Se podría leer la novela como parte de un hipertexto, ya que nos invita constantemente a explorar las referencias citadas para así descubrir la emoción que tiñe el texto. ${ }^{3}$ Una lectura contemporánea de ambas novelas se hace casi necesariamente acompañada de búsquedas en Youtube o Itunes, que nutren un lenguaje que formalmente expresa las limitaciones expresivas de sus personajes.

Este tipo de literatura se inscribe dentro lo que tanto la crítica literaria como la periodística han denominado las "literaturas del yo" y entendido como síntoma de la privatización de la experiencia. ${ }^{4}$ Concuerdo con que las "literaturas del yo" pueden leerse como un producto estético de un orden neoliberal transnacional donde la experiencia personal se vende al igual que cualquier producto de consumo bajo el slogan "basado en

Utilizo una noción de "hipertexto" que si bien se ancla en la definición de Gerard Genette en Palimpsestos: La literatura en segundo grado (1989), se relaciona más con la forma en que un texto presenta nexos que llevan al lector a otros textos, los cuales complejizan la linealidad y lo transforman en un sujeto activo que tiene la opción de profundizar su lectura al incorporar a esta otros textos.

4 Si bien la autoficción como categoría tiene una tradición principalmente dentro de las letras francesas -Serge Doubrovsky es quien, en 1977, acuña el termino autoficción y Philippe Lejeune, quien define el pacto autobiográfico-, los críticos españoles Manuel Alberca (2005) y Alicia Molero de la Iglesia (2006) coinciden en identificar las literaturas recientes, en primera persona, como muestra de una postura individualista frente a lo estético y lo social. Winston Manrique Sabogal, periodista cultural del diario $E l$ país, en su artículo "El yo asalta la literatura" (2008), analiza el fenómeno a partir de las contribuciones de diversos autores contemporáneos y críticos a la explicación del fenómeno y también resalta el carácter individualista de este tipo de literatura al calificarla como una expresión "acorde con estos tiempos de individualidad" (2). 
una historia real"; no obstante, las novelas que analizo demuestran que el gesto autorreferencial es más que una forma de satisfacer el morbo lector o las directrices del mercado de las letras. Lo individual, lo íntimo y lo personal no tiene por qué carecer de vínculo con lo social y lo político, o reducirse a un gesto cómplice de una economía de mercado del capitalismo tardío. A partir de los setenta -y en especial desde la contribución feminista- ha existido la tendencia a politizar lo íntimo. Anthony Giddens (1998) establece que el sujeto moderno tiene por primera vez opciones dentro de la construcción del yo y que por lo mismo sus elecciones en términos sexuales y amorosos están cargadas de fuerza política (20-21). Para las feministas, lo personal es político, y es específicamente en la parcialidad de la experiencia femenina que se legitima su punto de vista. Esto explica el rescate que hace la crítica feminista de textos autorreferenciales de mujeres escritos desde espacios cotidianos de reclusión doméstica similares, aunque contextualmente distantes, a aquellos representados por Casas y Erlan. Donna Harraway (1995) argumenta a favor del desarrollo de una objetividad feminista a partir de un punto de vista situado que describe como se percibe y se expresa un "yo" particular que no puede ser representado por medio de discursos particulares que pretenden llegar a todo el colectivo social (583). ${ }^{5}$ La figura del “yo", que mira y se expresa de forma situada, otorga legitimidad a la voz de la misma forma en que las prácticas de la intimidad son políticas en que se desafían o se subvierten las estructuras patriarcales en su realización.

Como una estrategia, la autoficción expone la lucha por definir una subjetividad masculina dentro de un marco social patriarcal que ofrece posibilidades restringidas para la codificación de sus emociones. No digo que el gesto autorreferencial agencie políticamente la subjetividad masculina heterosexual que se representa en las novelas, dado que ésta ya se articula en nuestra cultura a partir de una posición de privilegio; por el contrario, al hablar desde un lugar de intimidad los personajes masculinos representan los costos que tienen las exigencias patriarcales sobre subjetividades que dentro de las cuatro paredes de sus dormitorios se muestran vulnerables, enfermas, adoloridas y, por sobre todo, mudas

La situacionalidad descrita por Donna Harraway como argumento que justifica la estrategia de autoficción fue desarrollado por Nicolás Vicente dentro del marco de un Seminario de Graduación titulado: “En tono personal: la autoficción crítica en la novela chilena reciente", el cual dirigí en el segundo semestre del 2014 y con el cual completó el grado de Licenciado en Lengua y Literatura de la Pontificia Universidad Católica de Valparaíso en el 2014. 
ante la ausencia de un lenguaje que les permita comunicar sus emociones. Como ha señalado Butler (2009), la protesta se construye sobre la vulnerabilidad, y una de las formas más fidedignas de resistencia se da por medio de la unión de cuerpos vulnerables $(43)^{6}$. ¿Podríamos pensar estos textos narrados en primera persona como un intento por representar aquella dimensión de la experiencia masculina que el patriarcado esconde y que especialmente en Ocio se corporaliza en un cuerpo letárgico y enfermo? Si bien la argumentación de Butler se da a partir de comunidades afectadas por la guerra, la segregación y la represión, se matiza el concepto de vulnerabilidad al añadir a la situación de precariedad inherente a los cuerpos desvalidos una dimensión temporal y simbólica. La vulnerabilidad no es así inherente a un determinado cuerpo. Además se pregunta por los criterios que distinguen a los cuerpos que vale la pena salvar y defender en una situación de conflicto y a los que no (45). En nuestra configuración patriarcal el cuerpo masculino es un cuerpo blindado por el privilegio, sin embargo, las masculinidades representadas por Erlan y Casas llaman la atención sobre los cuerpos que somatizan la imposibilidad de comunicarse emocionalmente. La división entre mente y cuerpo ha sido negada desde la neurociencia por investigadores como Antonio Damasio (200o), quien piensa el cerebro y el soma como ámbitos interrelacionados, por lo que la vulnerabilidad del cuerpo masculino adolescente -en el caso de la novela de Erlan- y enfermo -en el caso de Casas-, da cuenta de una falta de sincronía entre los modelos de masculinidad heredados y la sensibilidad de los hombres que protagonizan las novelas. Según Butler (2009) el cuerpo es vulnerable al disciplinamiento de marcos simbólicos e interpretativos que nos preceden y es así como se imponen las nociones de género mucho antes de que conscientemente podamos resistir. Sin embargo, en su lectura, los cuerpos considerados vulnerables tienen el poder de unirse materialmente por medio de, por ejemplo, el lenguaje o el tacto, razón por la cual la reacción afectiva a la escritura que visibiliza el cuerpo herido o adolorido se lee desde su potencial político (70).

Ambas obras coinciden en la ausencia de figuras femeninas significativas, quizá el referente más tradicional en la enseñanza y mediación de los lenguajes del afecto. En el caso de El amor nos destrozará, somos testi-

\footnotetext{
"But what may be finally more true is that the subject that I am is bound to the subject I am not, that we each have the power to destroy and to be destroyed, and that we are bound to one another in this power and this precariousness. In this sense, we are all precarious lives" (43).
} 
gos del viaje formativo de Agustín, un niño que pasa por la adolescencia y llega a la adultez con una hermana muerta y una madre que producto del dolor se va encerrando en su locura. Por otro lado, en Ocio, la muerte de la madre representa el momento en que la comunicación entre los hombres de la familia colapsa debido a que ella funcionaba como una especie de intérprete emocional que cohesionaba al grupo familiar. Andrés, su protagonista, expresa sin rodeos las consecuencias de la ausencia de la madre y la función que ésta cumplía dentro del sistema doméstico: "Mi vieja era el cruce de caminos donde nos encontrábamos. Era el motor. Una familia necesita siempre un motor; porque si no es evidente la parálisis que se forma cuando varias personas se amontonan por mandatos biológicos" (13). La ausencia del dínamo familiar produce un cortocircuito comunicativo que paraliza a los hombres que quedan en la casa: "murió mi mamá y mi familia se desintegró. Quiero decir: seguimos viviendo bajo el mismo techo; pero cada uno en su zona, conservando ciertas costumbres, más por inercia que por convicción" (14). De este modo, observamos cómo ambas novelas representan a familias que sobreviven en un impasse en el que no se vislumbran nuevas formas de comunicación.

Los modelos en términos de género que emulan los protagonistas de las novelas de Casas y Erlan, si bien pertenecen al mundo de la industria cultural sajona, no son los hegemónicos en términos tradicionales. Las figuras masculinas en las que se repara se alinean a la figura del artista que vive en el borde del sistema, pero que no se desgasta o no tiene la energía para cambiarlo. No se distinguen así en las novelas indicios revolucionarios en términos estructurales. El cinismo es su respuesta ante los horrores del mundo, y los compromisos sociales y personales parecieran ser una ingenuidad.

\section{El amor nos destrozará: dormitorios, armarios y walkmans}

El amor nos destrozará es una novela de sensibilidad "noventera" publicada en el nuevo siglo. Transcurre en el Buenos Aires de la postdictadura y sigue la niñez y adolescencia de Agustín, un chico que, al igual que muchos de sus conciudadanos, no ha podido cerrar el proceso de duelo tras la muerte de un ser querido, en su caso su hermana mayor. A pesar de las conexiones entre la historia de la familia de Agustín y la de la nación, la novela de Erlan se resiste a la lectura alegórica de 
pensar el microcosmos familiar como correlato de esta, puesto que su foco se halla en la interioridad de su protagonista y la lucha de él no se centra en restablecer un sentido de justicia con la memoria de su hermana, sino en poder decodificar un mensaje secreto que de alguna forma educará su sensibilidad. ${ }^{7}$

Tampoco hay que descartar los elementos contextuales en los que se inserta la obra. La novela es del 2012, momento en que se publican una serie de novelas que presentan el ejercicio de recuperar una memoria como un marco formal para representar y elaborar las repercusiones que la experiencia traumática de la dictadura y sus abusos ha tenido en los hijos de la generación directamente impactada por la violencia de Estado. La llamada "novela de los hijos" trabaja lo que Marianne Hirsch (1997) define como "postmemoria" para elaborar el trauma desde los recuerdos, las historias, los artefactos artísticos o culturales y los silencios que heredan de la generación que sigue al evento traumático (112). Si bien la novela de Erlan es la de un hijo, y se distingue en ella un evento traumático al cual el protagonista no puede acceder directamente, no hay pistas de que el origen del trauma se deba a la violencia de Estado. La muerte de la hermana mayor desarticula la estructura familiar que no posee las estructuras emocionales para poder elaborar la pérdida: el silencio en torno a la ella se somatiza como parálisis y la familia deja de sentir el impulso por mejorarse. Se le niega así al protagonista, primero como niño y luego como adolescente, una explicación sobre la muerte de la hermana, y la sola mención de su nombre produce reacciones intensas en una familia que nunca se deshace de su ropa. Los integrantes del grupo familiar dejan de comunicarse y, al igual que en la novela de Casas, se transforman en una constelación de islas donde el niño es un satélite que con los años va alargando su órbita.

¿Qué salva a Agustín? Agustín acostumbra a encerrarse en el armario, en el baño, o, en cualquier espacio donde sus padres desaparezcan. Y es, precisamente, en un rincón del armario de su dormitorio donde encuentra un salvavidas. De la misma forma en que C.S. Lewis pasa a los niños por el umbral del armario hacia Narnia para salvarlos de los bombardeos alemanes, Erlan sitúa en el refugio de Agustín una puerta

En este sentido, el trabajo de interpretación realizado por Augustín es anti-alegórico, dado que, al contrario de lo planteado por Frederic Jameson sobre la novela del tercer mundo, no presupone una directa relación entre lo público y privado. 
hacia un mundo de intensidades radicalmente distintas a las que conoce. Agustín encuentra envueltos en una bolsa dos casetes grabados por su hermana. La oportunidad para escucharlos se aplaza por falta de un aparato para hacerlos sonar, pero en cuanto los escucha accede a paisajes emocionales absolutamente desconocidos y misteriosos. La música de la hermana muerta no se parece a nada de lo que haya escuchado y decodificar su mensaje se convierte en una tarea que acompaña al protagonista en los primeros años de su pubertad. ¿Quién canta? ¿Qué quieren decir las letras? ¿De dónde vienen esos sonidos?

Los casetes cobran una nueva relevancia cuando a Agustín le regalan un Walkman, ya que él había crecido sin juguetes. Agustín era un niño que pasaba horas mirando las manchas de humedad en el techo y que solo podía invitar a su vecino a jugar con la ropa vieja de su madre, por lo que este aparato es un hito dentro de su proceso formativo. El Walkman le permite seguir con el hábito de encerrarse y aislarse, los audífonos se transforman en un nuevo armario, pero en éste ya no está solo.

La novela de Erlan hace hincapié en la importancia de la música como contenedora y codificadora de emociones en la ausencia de figuras parentales capaces de orientar a una subjetividad adolescente que se configura dentro de una cotidianidad enrarecida por la muerte no elaborada de la hermana mayor. El Walkman resignifica el mundo al otorgarle banda sonora. Agustín dice: “Tengo quince años y soy el chico que despierta con los auriculares en el oído" (200). El personaje comienza a significar la experiencia a partir de la banda sonora que elige para cada momento, inscribiéndole así una intensidad emocional que no encuentra en su entorno. Un ejemplo de cómo la música potencia la realidad es la descripción que hace Agustín de una competencia de atletismo en que su mejor amigo de infancia corre para no solo ganar la carrera, sino también para superar sus complejos de infancia. La canción "Stickin' in my eye" de NOFX transforma a Alonso (el amigo) en un héroe épico que realiza la hazaña de dejar atrás a un niño gordito y acomplejado para transformarse en un adolescente que tal vez puede ganar en algo. La descripción de la carrera es cinematográfica, no solo porque lleva banda sonora, sino porque también presenta conflicto y desenlace. Alonso cree no poder, pero se sobrepone a la mirada desafiante de otro corredor y triunfa. Agustín se emociona y siente la carrera como propia y la experiencia se fija musicalizada en el recuerdo: "Al 
quitarme los auriculares, la tribuna había quedado en silencio. Y Alonso la enfrentaba con los brazos levantados" (129).

Para la generación $\mathrm{McOndo}^{8}$ el Walkman es su marca registrada. El poder pasear por la ciudad con banda sonora e ir así enfrentando individualmente las situaciones citadinas desde la emocionalidad de la música, marca un antes y un después. El Walkman otorga una mirada individual, un punto de vista al joven que por medio de la música se siente único dentro de la multitud. Si para muchos el Walkman se transformó en el símbolo de una generación desconectada, individualista y síntoma de la celebración neoliberal de los nuevos consumidores jóvenes, pienso en el Walkman más como un objeto simbólico que da paso al comienzo de una nueva relación con la música y lo social. Si bien la música siempre ha producido una impresión a nivel personal del que escucha, el Walkman produce un quiebre con la idea de música para multitudes, de la fiesta comunitaria, de los festivales y de la consigna cantada de los años setenta. La música no es solo puertas adentro, sino que resuena dentro del propio cuerpo, sin que nadie más la escuche incluso estando en la multitud. A nivel sensorial el Walkman instala una nueva forma de escuchar y por lo mismo una nueva forma de hacer música. El Walkman aísla los sonidos para que puedan ser escuchados de forma independiente en un audífono o el otro y, por sobre todo, el foco auditivo está exclusivamente en la música en el momento en que el resto de los sonidos son eliminados. Según el músico y escritor David Byrne (2014), la música esta íntimamente relacionada con la plataforma para la que es diseñada: clubes, estadios, autos o audífonos, por lo que hay bandas como la suya (The Talking Heads) que sonaban increíbles en un tugurio como el CBGB y que se perdían en los estadios deportivos donde bandas como U2 arrasan (14-15). El Walkman cambia la música y también al que la escucha, y El amor nos destrozará

\footnotetext{
La antología de cuentos $\mathrm{McOndo}$ (1996), compilada y prologada por Alberto Fuguet y Sergio Gómez, agrupa a una serie de escritores latinoamericanos nacidos después de 1962 que, según escritores, comparten una sensibilidad alejada de los marcos estéticos del realismo mágico y altamente interferida por los medios de comunicación y la experiencia urbana. Las voces de $\mathrm{McOndo}$ crecieron viendo los mismos programas de televisión, las mismas películas y leyendo novelas latinoamericanas que transcurrían en pueblos que sólo habían visto en postales (20). McOndo, en síntesis, reubica el origen simbólico de la imaginación literaria de su generación lejos de las voluptuosas selvas donde los patriarcas nunca mueren y cerca de las megalópolis latinoamericanas, donde los McDonalds, los condos y los computadores Macintosh son cada vez más parte del paisaje y la experiencia. McOndo logra no sólo el objetivo de internacionalizar una sensibilidad joven, urbana y mediatizada, sino que de paso catapulta la figura de Fuguet como la cara visible de un grupo de escritores que en un acto parricida se rebela ante la herencia del realismo mágico.
} 
hace la crónica de ese cambio unido al proceso de hacerse adulto y encontrar un lugar en la sociedad.

A partir del concepto de autonomía elaborado por Deleuze en La lógica del sentido, el crítico Shuhei Hosokawa (2012) distingue una diferencia entre la individualidad o incluso la alienación que se asocia al sujeto que escucha música en Walkman con la autonomía y una consecuente distancia positiva. Compartir un audífono con otra persona es compartir un secreto, es reconocer que se ve el mundo desde el mismo lugar y es por consiguiente el origen de una complicidad que impacta el proceso de construcción de subjetividad. Daniel Levitin en su estudio This is your Brain on Music (2006) insiste en nuestra vulnerabilidad frente a la música, especialmente aquella que escuchamos en nuestros años formativos. Cuando escuchamos música dejamos que nuestra subjetividad acoja las emociones e incluso las ideas políticas presentes en el mensaje musical. El goce musical deja entrar el mensaje musical a nuestra sala de estar, o directamente a nuestros audífonos cuando no nos estamos comunicando con nadie más (243). En esta línea pensemos en lo que significa en términos formativos para un joven encontrar claves sobre la experiencia humana en un conjunto de temas musicales y, como ocurre en la novela, encontrar una comunidad de sensibilidades afines que también están al tanto del secreto.

El casete que encuentra Agustín es un mixtape de canciones grabadas de la radio por su hermana. El mixtape narra de forma íntima, se opone a la lógica del disco que se vende porque hay una o dos canciones que se transforman en hits bajo el alero de un álbum que expresa un mensaje mayor. Los mixtape son recopilaciones de canciones elegidas a partir de la sensibilidad individual, por lo que su elección y distribución revelan un paisaje emocional individual. Regalar un mixtape es abrir la puerta a la intimidad y también describir, mediante la mezcla de canciones y del recorrido emocional por el que se lleva al auditor, los matices de una subjetivividad. El mixtape le pone banda sonora a la percepción e invita a ver el mundo desde la perspectiva de otro. El mixtape que encuentra Agustín abre una puerta hacia la sensibilidad de la hermana perdida, pero no puede aceder a esta sin investigar las canciones del listado, puesto que ellas despiertan en él sensaciones amorfas que no puede nombrar y que incluso lo asustan:

Una Guitarra. Una batería que empieza. Una voz de ultratumba. Tengo trece y uno de los casetes repite el mismo tema, en un 
lado y en el otro. El tema es diferente de cualquiera de los temas que se escuchan en los otros dos casetes. Suena así: como si las palomas muertas en la boca del gato tomaran fuerzas de donde no tienen, y empezaran a correr y llegasen a la punta de la terraza para tirarse al vacío. Así es el tema. No sé el título. No sé el nombre se la banda. No entiendo las letras de las canciones. (108)

La investigación en torno al orígen de las canciones es paralela al proceso de significar la muerte de la hermana y reconocer en las canciones una subjetividad que no conoció. Las canciones son de Joy Division, banda inglesa de culto post-punk, que al descubrirla también le permite al personaje descubrir a una tribu de jóvenes que circula por las tiendas de discos de galerías céntricas de Buenos Aires, vestidos con chaquetas de cuero y que, de alguna forma, sienten como él y su hermana muerta. Esta nueva familia urbana se transforma en la familia que le enseña a Augustín a ser hombre. El apoyo de la amistad le da la confianza para comenzar una vida sexual y sentimental con mujeres, la familia de un amigo lo invita a vivir en su casa y con su pandilla consiguen hacer un programa radial de trasnoche, trabajo que otorga sentido a su vida adolescente. El objetivo del programa de radio es similar al del mixtape: evocar esa ecclesia invisibilis de sensibilidades equivalentes para decirles a cada uno de los miembros que sintoniza en medio de la noche que no están solos.

Las referencias musicales que informan y conforman esta "autoficción formativa" están acompañadas por guiños a las películas comerciales norteamericanas de finales de los noventa como Pump up the Volume (1990) de Allan Moyle, y High Fidelity (2000) de Stephen Frears, donde la música y la radio funcionan como archivos emocionales de sus protagonistas. Sin embargo, las películas que ve el protagonista en el VHS de su mamá son principalmente los grandes éxitos del cine arte de la misma década como las películas de Peter Greenaway y Patrice Leconte. Agustín crece viendo las películas que su madre, al borde de la demencia, arrienda compulsivamente, y éstas también aportan a la construcción de una sensibilidad ya que, al igual que las canciones del mixtape de su hermana, son en un comienzo indescifrables. Las imágenes atiborradas y desasosegadoras de estas películas informan la subjetividad de un chico que quiere cargar de sentido su futuro y no es casualidad que el dependiente de la tienda de videos lo apode 
"Greenaway" y que este mismo sujeto luego oriente al protagonista en su educación musical y emocional cuando se lo encuentre de dependiente de una tienda de discos.

\section{Ocio: una vida horizontal}

A diferencia de El amor nos destrozará, Ocio no representa a un sujeto que transita de la niñez a la adultez, sino a un adulto joven atascado en una especie de adolescencia extendida y en negación con respecto a las demandas de la vida adulta. Al igual que en la novela de Erlan, Ocio elabora el impacto del duelo sobre el proceso formativo y la educación emocional masculina. La muerte de la madre de Andrés, el protagonista, produce un quiebre; la familia se desintegra y el protagonista pierde la motivación para estudiar, viajar y trabajar. Ahora vive en una familia de un padre y dos hijos hombres que describe como una especie de archipiélago de islas: "Mi viejo mira televisión en su pieza. Mi hermano acaba de salir a dar su vuelta nocturna: Pongo Abbey Road, de Los Beatles, y hojeo, de Roli, su colección de comics. Somos tres islas, es verdad" (72). Tres mundos independientes e incomunicados bajo un mismo techo. Todos sufren la ausencia de la madre, pero ninguno es capaz de articular su dolor. A las pocas noches de la muerte de la madre y esposa, el padre de Andrés lo despierta para decirle que se siente "raro" y le pide que lo acompañe y le toma la mano. Según Andrés: "estar en la cama y de la mano era una situación francamente insoportable" (17) de la que escapa mediante el sueño. En Ocio el lenguaje para codificar la pérdida de la madre no está disponible. El padre ordena compulsivamente la casa, el hermano trabaja sin tregua y el protagonista se encierra en su dormitorio a escuchar música y a leer. El título de la novela describe un estado psicológico que generalmente se asocia a una actividad que descomprime la rutina por medio del esparcimiento creativo. Sin embargo, el título en este caso pareciera ser eufemístico puesto que lo que se describe en la novela se acerca más a la acedia y al duelo, ya que el ocio no interrumpe actividades productivas, sino que se transforma en una forma de vivir en las cuales escuchar música y leer le permiten al protagonista enmarcar las emociones en la ausencia de un lenguaje que permita elaborarlas. La tristeza por la pérdida, primero de la madre y luego la de Roli -su mejor amigo quien muere de sobredosis-, se expresa como Ocio. Según Roli, un experto en historietas, todos los superhéroes tienen un familiar 
muerto. Su súper poder vendría entonces de la forma en que trabajan su duelo. Pero este no es el caso del protagonista, debido a que se entrega a una parálisis que toma forma de acedia, abulia e intoxicación, hechos y estados que lo acercan cada vez más a la muerte. Leer y escuchar los discos de Los Beatles y Led Zeppelin serían así más que soportes para la evasión, actividades salvavidas que le dan forma a los afectos que siguen a la pérdida. Los jóvenes clasemedieros del Buenos Aires representados por Casas y Erlan hablan de libros, discos y películas para no hablar de sus penas, de mujeres, de temas sociales, de sus familias. Los consumos mediáticos se parecen en Ocio a los consumos de drogas que llenan el día y de a poco la vida. Ante la posibilidad de que la vida de Andrés cambie, su respuesta es rotunda:

Al ritmo que voy me parece imposible (...) no hago nada o casi nada.

-Nadie hace nada -dijo Rolo sonriendo-. Pero ¿qué clase de nada? Es decir... ¿Te quedás levitando en un rincón? Porque si podés levitar ahí ya tenemos un negocio.

-Escucho música, me masturbo, como y cago -le contesté. (39)

Estar en la calle tomando algo y escuchando música es una actividad que llena el día y el cariño por los amigos se expresa interesándose en las mismas revistas, discos y películas. Es a partir de los universos referenciales compartidos que se elabora un lenguaje que genera vínculos afectivos que, en el caso de la novela de Erlan genera comunidad y, en el caso de Casas, puebla el impasse emocional del duelo de sonido y complicidad.

La afición por los discos, los libros y las historietas que caracteriza al joven que se niega a hacer el pacto de integración a la sociabilidad burguesa no es en el caso de Andrés transformada en energía creativa, sino, por el contrario, en abulia y enfermedad. Después de las dos pérdidas (y una considerable cantidad de drogas) el hígado de Andrés se vuelve gelatina y lo que antes era un encierro voluntario en su dormitorio con los Beatles y Led Zeppelin se transforma en condición de supervivencia. Declararse enfermo y postrado en la temprana adultez, uno de los momentos supuestamente más energéticos del guion vital, alude a la idea de vulnerabilidad que esbocé arriba. Si pensamos en la obra como una "autoficción formativa" queda de manifiesto la intención de visibilizar el dolor del protagonista, quien a diferencia de su padre se entrega a los es- 
tragos de la depresión. En otras palabras, se da el lujo de estar deprimido, de seguir siendo un adolescente encerrado en su dormitorio, porque a diferencia de su padre y de su hermano deja que sus emociones tomen posesión de su cuerpo aun cuando sea enfermándolo. El cuerpo masculino es en Ocio vulnerable a las emociones y el autor/narrador/personaje explora el impasse escuchando música.

Quedarse en cama, asumir el costo físico del dolor emocional es un gesto que la tradición literaria ha caracterizado como femenino. Imágenes de mujeres del siglo XIX con jaqueca nos dicen que la cama es un espacio eminentemente femenino y posiblemente también que el hombre que la elige se niega a asumir las directrices del tipo de masculinidad que hereda. Para críticas feministas como Elaine Showalter (1985) la enfermedad que lleva a la cama o la histeria pueden, en el caso de las mujeres, ser leídas como formas de resistencia a las posibilidades expresivas del género. En el caso de los hombres, el shell shock o lo que hoy se conoce como stress postraumático producto de los horrores de la guerra resultan, según Showalter, de la prohibición de expresar emociones asociadas al dolor (171). El desamparo del soldado es en esta lectura equivalente a la soledad de la mujer cuya expresión es coartada por el sistema patriarcal y la consecuencia es la enfermedad (190). El patriarcado no otorga un vocabulario para la expresión del dolor masculino y aun cuando Andrés no va a la guerra comparte el desamparo de la mujer decimonónica que se encierra en su dormitorio. Sin embargo, el encierro de Andrés, al igual que el de la madre de Agustín, contempla el consumo compulsivo de información mediatizada. Las películas en VHS de la señora que de a poco sucumbe a la locura tienen un paralelo en las novelas, la televisión y por sobre todo en los discos que escucha una y otra vez Andrés. En el caso de la madre de la novela de Erlan, el consumo mediático no implica una educación sentimental como es el caso del hijo que espía las películas desde el armario cuando esta se duerme frente al televisor. Pareciera que Andrés se está constantemente preparando para ser un hombre más culto, más experto en las cosas que le interesan, por lo que asume tareas de lectura extensas, sin embargo, esta educación sentimental no lo saca de su dormitorio, sino que al igual que una señora victoriana lo encierra más. La novela termina sin cambios, solo con la constatación de que los hombres que sobreviven a la madre siempre serán tres islas viviendo juntos. En esto se diferencian las novelas de Casas y Erlan. Para el último la música y las películas son una salida a la parálisis emocional y al encierro 
doméstico en el que crece el protagonista, ya que convocan a una comunidad que si bien no cambiará el mundo con su rebeldía, sí se cambian a sí mismos al encontrar modelos emocionales más allá de los referentes familiares y nacionales. En el caso de Ocio, las novelas, las historietas y la música son lo único que le permite comunicarse emocionalmente con otros hombres, pero hay un determinismo en la vida del hombre joven que busca intensidad marcado por la siempre abierta salida de la autodestrucción. El cuerpo enfermo de hepatitis del protagonista evidencia la necesidad de tomarse un tiempo para clarificar su relación con una crisis comunicacional permanente que se ha transformado en una nueva realidad. La enfermedad como hiato, impasse, parálisis, corporaliza los problemas de Andrés, un joven que no quiere hacer el pacto de integración que lo transformaría en otro hombre que llega de su casa al trabajo a comer frente al televisor como su padre y su hermano.

A propósito de la enfermedad de Andrés, quisiera cerrar con la imagen de un cuerpo vulnerable. El preadolescente solo y flaco, en calzoncillos viejos y con el elástico ajado, que se encierra en el baño representado por Erlan, y el joven que transpira helado y postrado de Casas. Estos cuerpos llaman la atención sobre un momento que podríamos entender como proto-político en relación a la configuración de una demanda masculina al modelo patriarcal. La incomodidad de las masculinidades representadas en las novelas no es articulada por sus protagonistas, pero sí visibilizada mediante la circulación del texto mismo. Podemos quizás comparar los impulsos autodestructivos y evasivos de los personajes con los dolores, las jaquecas, la histeria representada en las mujeres que pueblan la novela del final del siglo XIX. La incomodidad se somatiza en un cuerpo vulnerable al dolor que la psique no puede procesar debido a la falta de un lenguaje. La loca en el desván es en estas novelas el hombre encerrado que combate la soledad escuchando los mismos discos una y otra vez.

La novela de formación se desarticula en los textos analizados. En Casas el protagonista no sale al mundo a enfrentar pruebas que lo fortalecerán, sino que el exterior, es decir el espacio más allá de su dormitorio y equiparable al espacio de la aventura en el cual se aprenden lecciones de vida, es una especie de prolongación del dormitorio. En la calle y los boliches el protagonista sigue haciendo nada. Un estilo de vida diletante y el consumo de drogas absorbe cualquier impulso productivo que tanto el protagonista como su amigo Roli intentan llevar a cabo. Andrés se salva de la muerte, el destino de su mejor amigo, porque le tiene un 
poco más de miedo a las drogas, pero en ambos el hacer "nada" se vincula directamente con el maltrato a un cuerpo joven equipado para la vida productiva. El texto llama la atención hacia los elementos formativos precisamente por medio de la resistencia que el joven protagonista pone al programa de educación e inserción característico de la novela formativa. Si bien el protagonista sobrevive, no hace más que esto, ya que la novela cierra de la misma forma que abre: con el protagonista en cama escuchando música. Finalmente, Ocio es un texto breve, una nouvelle que, si bien tiene como voz principal la primera persona, no presenta un arco narrativo evidente y la reflexión del protagonista no se da en torno a descubrimientos sobre sí mismo o el mundo que lo rodea, sino que el objetivo es simplemente sobrevivir al dolor, a la soledad, al desamparo y por sobre todo a las expectativas que se tienen en torno a una masculinidad joven.

El amor nos destrozará se alinea más con el modelo formativo tradicional, sin embargo, su gran diferencia radica en que el protagonista no sale a un mundo desconocido a superar pruebas, sino que las pruebas las debe superar dentro del espacio de lo familiar. Las dificultades las enfrenta antes de estar preparado para hacerlo, en la niñez y temprana adolescencia, y lo desconocido se personifica en una madre y un padre que se deterioran velozmente después de la muerte de su hermana. Agustín sale al mundo al igual que Atreyu y Bastián, los héroes de La historia sin fin, película que arrendaba ritualmente con su vecino, armado con un amuleto que lo orienta y protege. El Auryn, amuleto mágico que protegía a Bastián en la película, son para Agustín los mixtapes de la hermana. ${ }^{9}$ Estos lo orientarán hacia una nueva comunidad, lugar donde las canciones son el lenguaje de las emociones.

\section{Referencias bibliográficas}

Ahmed, Sara. The Cultural Politics of Emotion. New York, Routledge, 2004.

Alberca, Manuel. “¿Existe la autoficción hispanoamericana?”. Cuadernos del CILHA, vol.7, no. 8, 2005, pp. 115-127.

Connell R.W. Masculinities. Berkeley, University of California Press, 2005.

$9 \quad$ El Auryn es el amuleto mágico que orienta y protege a Batián, protagonista de la Historia sin fin de Michael Ende. El amuleto representa dos serpientes entrelazadas que se muerden la cola. 
Damasio, Antonio. The feeling of What Happens: Body and Emotion in the Making of Consciousness. Orlando, Harcourt Incorporated, 2000.

Beasley-Murray, Jon. "El afecto y la poshegemonía”. Estudios, vol.16, no.31, 2008, pp. 41-69.

Berlant, Lauren. Cruel optimism. Durham, Duke UP, 2011.

Butler, Judith. Gender Trouble. New York, Routledge Press, 1999.

Frames of War. When Life is Grievable. New York, Verso, 2009.

Byrne, David. How Music Works. San Francisco, McSweeney's, 2014.

Casas, Fabián. Ocio. Barcelona, Alpha Decay, 2012.

Erlan, Diego. El amor nos destrozará. Buenos Aires, Tusquets, 2012.

Fuguet, Alberto, Gómez, Sergio (Eds.). McOndo. Barcelona, Mondadori, 1996.

Genette, Gerard. Palimpsestos: La literatura en segundo grado. Madrid, Taurus, 1989.

Giddens, Anthony. La transformación de la intimidad en Occidente. Madrid, Cátedra, 1998.

Harraway, J.D. “Conocimientos situados: la cuestión científica en el feminismo y el privilegio de la perspectiva parcial”. Ciencia, cyborgs y mujeres. La reinvención de la naturleza. Madrid, Cátedra, 1995.

Hirsh, Marianne. Family Frames. Photography, Narrative and Postmemory. Cambridge, Harvard UP, 1997.

Hosokawa, Shuhei. "The Walkman Effect". The Oxford Handbook of Sound Studies. Eds. Trevor Pinch \& Karin Bijstereldt. Oxford, Oxford University Press, 2012.

Landsberg, Allison. Prosthetic Memory: The Transformation of American Remembrance in the Age of Mass Culture. New York, Columbia UP, 2004.

Levitin, Daniel. This is Your Brain on Music. New York, Dutton, 2006.

Manrique Sabogal, W. "El yo asalta a la literatura”. El País, 13 de septiembre, 2008, pp. 2.

Molero de la Iglesia, Alicia. "Figuras y significados de la autonovelación." Espéculo: Revista de Estudios Literarios, no. 33, 2006, p. 72. 
Showalter, Elaine. The Female Malady: Women, Madness and English Culture, 1830-1980. New York, Pantheon Books, 1985.

Seidler, Victor J. Masculinidades. Culturas globales y vidas intimas. Trad. de Josep Sarret Grau. Barcelona, Editorial Montesinos, 2007. 